\title{
A Administração Pública municipal no cumprimento das funções da cidade por meio de políticas públicas e controles sustentáveis em Fortaleza/CE
}

Municipal Public Administration in fulfilling city functions through sustainable public policies and surveillance in Fortaleza/CE

\section{Lívia Brandão Mota Cavalcanti ${ }^{1}$}

\section{RESUMO}

O objetivo deste artigo consiste em analisar as relações existentes entre políticas públicas municipais - as quais devem estar sintonizadas, na prática, com as necessidades da população, por meio do atendimento às funções da cidade - e os controles exercidos pela Administração Pública, em especial, de Fortaleza/CE. Quanto ao método de pesquisa, tem-se que a revisão de literatura apoiou-se em doutrinas e trabalhos científicos desenvolvidos na área, bem como em documentos oficiais, tais como cartilhas e manuais de práticas públicas. Sendo assim, o desenvolvimento deste trabalho permite confirmar a relevância das funções da cidade como critérios embasadores de formulação de políticas públicas atentas às realidades dos centros urbanos em conjunto aos controles exercidos pela Administração Pública sobre seus entes e os particulares.

Palavras-Chave: Funções da Cidade. Políticas Públicas. Sustentabilidade. Controle. Tribunais de Contas.

\section{ABSTRACT}

The objective of the present paper is to analyze the existing relations between municipal public policies - which must, in practice, be attuned to the needs of the population, by attending to the city's functions - and the

1 Especialista em Direito e Processos Administrativos pela Universidade de Fortaleza (Unifor). Bacharela em Direito pela Universidade Federal do Ceará (UFC). Advogada OAB/CE 36.213. E-mail: liviabrandaomota@ hotmail.com 
controls exercised by the Public Administration, in particular, in Fortaleza/CE. As for the research method, the literature review was based on doctrines and scientific works developed in the area, as well as on official documents, such as booklets and manuals of public practices. Thus, the development of this work allows to confirm the relevance of the city's functions as basic criteria for the formulation of public policies that are attentive to the realities of urban centers together with the controls exercised by the Public Administration over their entities and the society.

Keywords: City Functions. Public Policies. Sustainability. Control. Courts of Accounts.

Recebido: 02-08-2020

Aprovado: 09-10-2020

\section{INTRODUÇÃO}

$\mathrm{O}$ atendimento às funções da cidade, como balizas de um planejamento urbano, possibilita o gozo pleno de direitos sociais estabelecidos na Constituição Federal de 1988. Tal cumprimento dar-se-á por meio de execução de políticas públicas pela Administração Pública Municipal, considerando a relação entre tais funções e o objetivo específico da intervenção.

Coerente à sistemática de melhoramentos públicos baseados em atender necessidades presentes e futuras de maneira sustentável, surge da própria Administração o interesse em exercer o controle de tal forma que atenda aos imperativos evidenciados pelas funções.

A definição do tema surge pelo interesse em compreender alguns dos mecanismos atuais que são utilizados nas fases de planejamento dos investimentos públicos e de suas execuções pelas gestões públicas, combinados com a fiscalização aplicada pelos órgãos de controle tanto sobre os particulares quanto sobre o Poder Público. O estudo considera o recorte epistemológico do município de Fortaleza/CE e o Tribunal de Contas do 
Estado do Ceará, dadas as políticas correntemente aplicadas de investimentos e controles sustentáveis.

Os tópicos foram desenvolvidos de maneira a compreender o dever da Administração Pública de atenção às funções da cidade e as repercussões na qualidade das políticas públicas intentadas, pois tornam os melhoramentos e gastos públicos produtivos a longo prazo e em consonância com preocupações já evidenciadas pelo ordenamento jurídico brasileiro.

Por fim, intentou-se, por meio deste trabalho, contribuir para a observação da importância do atendimento das funções da cidade como garantidoras de políticas públicas que visem ao não esgotamento dos recursos disponíveis e de controles efetivos e harmônicos com ambientes urbanos sustentáveis.

\section{A ADMINISTRAÇÃO PÚBLICA MUNICIPAL NO CUMPRI- MENTO DAS FUNÇÕES DA CIDADE}

As funções da cidade são institutos identificados pela doutrina (SILVA, 2011) como alguns dos direitos sociais estabelecidos pela Constituição Federal de 1988. Constituem-se em quatro funções elementares quais sejam habitar, laborar, circular e recrear - concatenadas por técnicos da Ciência do Urbanismo e documentadas na Carta de Atenas.

Pela transdisciplinaridade presente no tema, ocorreu por bem a incorporação dos seus conceitos nas áreas dos Direitos Urbanístico, Administrativo e Ambiental com o intuito de melhor compreender as demandas de todos que usufruem dos espaços urbanos e torná-los sustentáveis.

Em se tratando de competência constitucional, por expressão dos incisos VIII e IX do artigo 30 da CF/1988, cabe ao ente municipal organizar a ocupação do solo urbano e fiscalizá-la, como aplicação do raciocínio de que funções de interesse local pertencem aos menores entes.

Tal planejamento acontece em consonância com os das esferas 
estadual e federal, já que estas constantemente influenciam a tomada de decisões dos gestores municipais (ZAGO, 2014). Percebe-se, então, que, numa visão sistemática, a repartição de competências é um instituto o qual mais visa conciliar e facilitar a implementação das metas de cada ente do que distanciá-los entre si ou de suas respectivas funções. Portanto, partindo da programação de ações conjuntas, tem-se a possibilidade de a esfera municipal promover as funções urbanísticas.

Os municípios, como entes federados que são e dotados das competências constitucionais supracitadas, encontram-se responsáveis pela prática de políticas públicas destinadas à efetivação das funções da cidade ou que contribuam de maneira indireta para a sua perpetuação. Ainda, ocupam o papel de ente fiscalizador das atividades dos particulares. Estas três perspectivas permitem o necessário cumprimento das funções da cidade pela Administração Pública Municipal.

\section{O MUNICÍPIO COMO PROMOVEDOR IMEDIATO DAS FUNÇÕES DA CIDADE E COMO AGENTE MEDIATO DAS FUNÇÕES DA CIDADE}

Na primeira possibilidade, quando o município age como promovedor imediato das funções da cidade, o papel do poder público municipal é de sujeito ativo, cumprindo diretamente estas funções quando interfere na cidade por intermédio de políticas públicas. Quer dizer, tais políticas intentadas pelo Estado são as responsáveis pela implementação das funções dos espaços urbanos.

Ao Município caberá a ampla execução das políticas públicas, inclusive em matéria ambiental, no seu interesse local, restrita apenas, quando for o caso, às hipóteses sujeitas às normas gerais (União) e específicas (Estado-membro) e desde que estas estejam em consonância com as Constituições Federal e Es- 


\section{Entrole}

tadual e as normas internacionais de direitos humanos, implementando medidas administrativas e legislativas direcionadas à conservação do meio ambiente (por exemplo, instalação de parques e de áreas arborizadas, incentivo ao uso de transporte limpo e a edificações que utilizem energias renováveis, atividades educativas, programa de reciclagem, dentre outros) e a práticas empresariais sustentáveis no âmbito de seus limites municipais (ARANHA FILHO, 2016, p. 472).

Em sendo promovedor imediato destas funções, estimula, por exemplo, políticas de planejamento e adaptação de infraestrutura para mobilidade urbana de pessoas com deficiência. Aqui o ente público age de maneira a permitir que parte da população possa, mais que circular livremente pela zona urbana equipada com tal política, acessar seu locus de trabalho e ambientes de lazer. Desse modo, o Município de maneira direta aplica melhoramentos cujos desdobramentos constituir-se-ão na efetivação das funções da cidade, sem olvidar do atendimento a aquisições sustentáveis, pois, no presente caso, atende-se à sua dimensão social.

No tocante às decisões do Poder Judiciário, os tribunais, há tempos, recorrem às funções elementares do espaço urbano de maneira a reconhecer o papel do Estado como ente promotor de políticas voltadas à dignidade do citadino.

AGRAVO DE INSTRUMENTO - AÇÃO CIVIL PÚBLICA DIREITO URBANÍSTICO - PLANO DIRETOR - VINCULAÇÃO DA ADMINISTRAÇÃO PÚBLICA - CRITÉRIO OBJETIVO - RECURSO DESPROVIDO. As exigências urbanísticas desenvolveram-se de tal modo nas nações civilizadas e passaram a pedir soluções jurídicas, que propiciaram a criação em nossos dias do Direito Urbanístico, ramo do Direito Público destinado ao estudo e formulação dos princípios e normas que devem reger os espaços habitáveis. $\mathrm{Na}$ amplitude desse conceito, o texto pretérito, em confronto com a nova Carta Política, ou a ela se amolda ou, na hipótese contrária, é por ela revogado; destarte o Plano Diretor do Município vincula a Administração Pública, constituindo-se em critério objetivo 
para aferição das áreas em que o homem venha a exercer coletivamente qualquer de suas quatro funções essenciais na comunidade; habitação, trabalho, circulação e recreação (TJ-SC - AI: 14727 SC 1998.001472-7, Relator: Anselmo Cerello, Data de Julgamento: 15/04/1999, Segunda Câmara de Direito Civil, Data de Publicação: Agravo de Instrumento n. 98.001472-7, da Capital) (grifo nosso).

A perspectiva do município como agente direto das funções da cidade talvez seja a oportunidade na qual o ente público mais facilmente as concretiza. Contudo, em um sistema onde existem atividades exercidas também pela sociedade civil e que se encontra em constante modificação, não cabe menosprezar as tarefas de colaborar com as demais políticas públicas e de fiscalizar os particulares para implementação de medidas sob o crivo das funções urbanas.

$\mathrm{Na}$ segunda possibilidade, quando o município é agente mediato das funções da cidade, seu papel permanece de sujeito ativo, porém, neste caso, indiretamente, ver-se-ão cumpridas estas funções por meio de políticas públicas. Nesta classificação, tomam-se atividades que indiretamente promovem as funções dos espaços urbanos, respeitando e contribuindo para que as pessoas possam habitar, laborar, circular e recrear.

A construção de hospitais e leitos de internação - programa de suma importância para a saúde da população, principalmente em períodos de pandemia -, relaciona-se com as funções urbanas por auxiliar na qualidade de vida dos habitantes e permitir que todos possam levar adiante suas rotinas pessoais e laborais. Contudo, não há uma relação direta entre tais benefícios e as qualificadoras de habitação, labor, mobilidade urbana e recreação. Em outras palavras, estes programas são concretizados, pois pertencem a uma rede de necessidades da sociedade e promovem indiretamente funções urbanísticas.

As políticas públicas, sejam promovedoras diretas ou indiretas das funções da cidade, são incorporadas à vida urbana por meio das contratações públicas. Qualquer aquisição de ordem material deve ser feita sob a 
obediência das normas que regem as compras públicas, em especial a Lei 8.666 de 1993.

Com o acréscimo do princípio do desenvolvimento nacional sustentável ao artigo $3^{\circ}$ desta lei pela Lei 12.349 de 2010, infere-se que não há legalmente como desenvolver um sistema de compras públicas sem, contudo, atender critérios de sustentabilidade. Uma outra conclusão seria: não há como efetivar as funções da cidade por outro caminho que não seja a observância das dimensões da sustentabilidade em cada aquisição oriunda do Poder Público municipal.

Isto porque o ordenamento jurídico brasileiro vem constantemente incluindo demandas para atender a imperativos sustentáveis por necessidade de sobrevivência das presentes e futuras gerações.

As alterações trazidas à legislação infraconstitucional têm por base a Constituição Federal de 1988, constituindo-se a proteção ambiental um dever de quem contrata pelo Poder Público. Por essa razão, acredita-se que a promoção do desenvolvimento sustentável deve ser considerada uma finalidade absoluta do administrador público (sem ser relativizada) na realização das contratações públicas, influenciando a forma de interpretação das novas legislações [...] Acredita-se, portanto, que enquanto a norma de licitações sustentáveis não envolver a sustentabilidade em suas múltiplas dimensões, se poderá considerá-la com sua eficácia mitigada, visto que acaba por não atingir de forma plena o objetivo pretendido pela norma (SILVA; KESSLER, 2016, p. 164).

Além de o Estado deter um alto poder de compra, o dever legal de implementar contratações sustentáveis remodela o padrão de consumo do Poder Público, bem como o da própria sociedade a qual frequentemente contrata com os entes públicos e com os demais particulares entre si (ARENAS, 2016). Nada mais associativo do que afirmar que tal imperativo é determinante para o setor público e indicativo para o setor privado, pois induz o mesmo padrão de consumo nas contratações não governamentais. 
Em relação aos programas aplicáveis pelos entes municipais, requer-se bom planejamento urbano, sem o qual não se alcançarão as funções da cidade, seja de maneira imediata ou mediata. Convém reiterar que o planejamento é a fase possibilitadora de coadunar os objetivos das políticas municipais, ou seja, conferir harmonia para que as medidas tomadas sejam aplicáveis em sua máxima efetividade. Tudo isso advém da exigência constitucional pela boa administração e governança, segundo o artigo 37 da CF/1988 (PROVIN, 2019).

Pode-se afirmar, além disso, que um bom sistema de gestão será internalizado pelo conjunto quanto mais forte for sua implementação nos setores hierarquicamente mais elevados (BARBIERE, 2012, p. 170), justamente por influenciarem novos padrões de consumo e comportamento. Destarte, infere-se a relevância de tomadas de decisão pelas gestões municipais em prol de máxima efetividade dos produtos e serviços contratados e postos à disposição da população.

\footnotetext{
São, ainda, as licitações e contratações administrativas, instrumentos de implementação de políticas públicas no âmbito econômico e social, um meio de incentivo e fomento a atividades socialmente desejáveis, visto os altos recursos financeiros alocados pelo Estado para as contratações administrativas. É o que podemos chamar de funções sociais das licitações e contratos administrativos, e que compõe sua relevância político-econômica (ARENAS, 2016, p. 123).
}

Incluídas neste necessário planejamento, as políticas de boas práticas atualmente significam termos bem estabelecidos quanto à eficiência e à sustentabilidade dos procedimentos administrativos. Neste sentido, o Tribunal de Contas da União entendeu que considerar os vieses da sustentabilidade nas contratações públicas contribuem para a boa governança.

ACORDAM os Ministros do Tribunal de Contas da União, reunidos em Sessão do Plenário, ante as razões expostas pelo 
Relator, em:

9.1. recomendar ao Ministério do Planejamento, Orçamento e Gestão que apresente, em 90 (noventa) dias, um plano de ação visando a orientar e a incentivar todos os órgãos e entidades da Administração Pública Federal a adotarem medidas para o aumento da sustentabilidade e eficiência no uso de recursos naturais, em especial energia elétrica, água e papel, considerando a adesão do País aos acordos internacionais: Agenda 21, Convenção-Quadro das Nações Unidas sobre Mudança do Clima e Processo Marrakech, bem como o disposto na Lei $\mathrm{n}^{\circ} 12.187$, de 29 de dezembro de 2009, na Lei $\mathrm{n}^{\circ} 9.433$, de 8 de janeiro de 1997, na Lei ${ }^{0} 10.295$, de 17 de outubro de 2001, no Decreto $\mathrm{n}^{\circ} 5.940$, de 25 de outubro de 2006, e na Instrução Normativa SLTI/MP n ${ }^{\circ} 1$, de 19 de janeiro de 2010;

[...]

9.4. recomendar ao Ministério do Meio Ambiente, ao Ministério do Planejamento, Orçamento e Gestão e à Eletrobrás, no que lhe competem, que:

9.4.1. ampliem a divulgação de seus respectivos programas - A3P, PEG e Procel EPP - perante a Administração Pública Federal, informando sobre o apoio prestado e sobre a existência de banco de dados contendo boas práticas bem como disponibilizem links de acesso, em suas respectivas páginas na internet, dos outros dois programas de apoio e de outros sites com informações sobre práticas sustentáveis;

[...]

9.4.3. avaliem a estrutura, respectivamente, da Agenda Ambiental da Administração Pública, do Programa de Eficiência do Gasto e do Subprograma Procel Eficiência Energética em Prédios Públicos, visando dotá-los das condições necessárias para fomentar a adoção de ações voltadas para o uso racional de recursos naturais na Administração Pública Federal;

$[\ldots]$

9.8. recomendar ao Ministério do Planejamento, Orçamento e Gestão que incentive os órgãos e instituições públicas federais a adotarem um modelo de gestão organizacional estruturado na implementação de ações voltadas ao uso racional de recursos naturais, a exemplo das orientações fornecidas pelos Programas A3P, PEG e Procel EPP;

(TCU. Processo n. ${ }^{\circ}$ TC $017.517 / 2010-9$, Acórdão n. ${ }^{\circ}$ 
1.752/2011 - Plenário. Ata n 25/2011 - Plenário. Data da Sessão: 29/6/2011 - Ordinária) (grifos nossos).

Nesta perspectiva, desenvolveu-se a Agenda Ambiental na Administração Pública - A3P, formada por inúmeros órgãos dos Poderes Executivo, Legislativo e Judiciário e das esferas federal, estadual e municipal. O intuito de estabelecer modelos de gestão pública sustentáveis em todas as suas dimensões é a grande finalidade do projeto, o que, consequentemente, facilita práticas promovedoras das funções da cidade.

\begin{abstract}
A A3P é um programa que busca incorporar os princípios da responsabilidade socioambiental nas atividades da Administração Pública, através de estímulo a determinadas ações que vão, desde uma mudança nos investimentos, compras e contratações de serviços pelo governo, passando pela sensibilização e capacitação dos servidores, pela gestão adequada dos recursos naturais utilizados e resíduos gerados, até a promoção da melhoria da qualidade de vida no ambiente de trabalho (CAVALCANTE, 2012, p. 196).
\end{abstract}

Além de viabilizar a democratização sustentável de programas de habitação, geração de empregos, mobilidade urbana e lazer, a A3P coaduna e influencia os planejamentos dos diversos entes e órgãos no mesmo sentido: desenvolvimento interno de boas práticas, controle interno e externo voltados não exclusivamente para finalidade econômica e aplicação de políticas públicas sensíveis às intensas mudanças da era atual.

No estado do Ceará, têm-se incluído alguns municípios, como o de Fortaleza, conforme lista das instituições parceiras no sítio eletrônico do Ministério do Meio Ambiente. Reconhece-se, portanto, o compromisso do município em planejar e executar políticas públicas as quais contribuam com as diversas dimensões da sustentabilidade e, assim, efetivem as funções da cidade. 


\section{O MUNICÍPIO COMO FISCALIZADOR DAS ATIVIDADES DOS PARTICULARES}

A terceira perspectiva na qual o ente municipal contribui com as funções da cidade é justamente quando este ocupa o papel de fiscalizador das demais atividades exercidas pela sociedade civil, seja em parceria com o Poder Público ou agindo como exploradores de atividade econômica.

O controle das inúmeras atividades dos particulares encontra determinação na Constituição Federal em seu artigo 174 e considerável parte dessa fiscalização, em prol da efetivação das funções da cidade, acontece observando-se as competências discutidas anteriormente, notadamente as relacionadas com o interesse local.

ADMINISTRATIVO - MANDADO DE SEGURANÇA MANIFESTAÇÃO ARTÍSTICA CONHECIDA COMO "ESTÁTUA VIVA" - APRESENTAÇÃO EM LOGRADOUROS PÚBLICOS - EXIGÊNCIA DE LICENÇA ADMINISTRATIVA - INADMISSIBILIDADE - VIOLAÇÃO DO DIREITO À LIBERDADE DE EXPRESSÃO ARTÍSTICA - ART. 5, IX, DA CONSTITUIÇÃO FEDERAL - CONCESSÃO DA SEGURANÇA QUE SE CONFIRMA. 1- A expressão pública da arte denominada "estátua viva" constitui exercício do direito à liberdade de expressão artística, instituído pelo art. $5^{\circ}$, IX, da Constituição Federal de 1988. 2- A exigência de licença administrativa constitui norma restritiva da liberdade, de modo que sua sustentação somente se faria validamente, no caso concreto, pela confrontação legítima do exercício da liberdade do impetrante com outros direitos, em que restasse evidenciada a necessidade de tutela destes, em detrimento daquele. 3- Os espaços públicos são para uso público, de qualquer pessoa do povo, sem que isso se converta em apropriação privada do espaço de todos. De outro lado, a regulamentação da utilização dos espaços públicos não pode se converter em apropriação deles pela Administração Pública, de modo a sujeitar a sua fruição, por quem quer que seja, a um alvará, cuja exigência não está autorizada pela Constituição Federal. Afinal, a vocação dos espaços públicos, de uso comum do povo, já tem sua definição 
intrínseca, constituindo as praças locais de encontro e convivência social, apropriadas às manifestações artísticas espontâneas. 4- A exigência de licença administrativa extrapola em muito a competência de ordenação do espaço urbano e perde de vista a própria função da cidade, razão da outorga da competência constitucional, que é possibilitar o bem-estar de seus habitantes, pelas funções de habitação, trabalho, circulação e recreação, que tem como primeira manifestação a expressão pública da arte popular espontânea. 6Configurada a violação do direito líquido e certo do impetrante, por ato ilegal da autoridade municipal, confirma-se a sentença que concedeu a segurança (TJ-MG 100240587048830011 MG 1.0024.05.870488-3/001(1), Relator: MAURÍCIO BARROS, Data de Julgamento: 06/03/2007, Data de Publicação: 23/03/2007) (grifo nosso).

Pertencentes às matérias de interesse local, os conteúdos ambientais são um excelente paradigma sobre quais atividades dos particulares a Administração Pública municipal deve exercer tal controle e de que forma ele deve acontecer. Logo, a questão volta-se para quais instrumentos legais o ente público pode dispor a fim de exercer atos de fiscalização para que se concretizem as funções dos espaços urbanos (FARIAS, 2017).

Inicialmente, por servir de sustentação para as modificações do espaço urbano, o princípio da precaução, antevendo consequências danosas e incertas ao ambiente em sentido lato, contribui para que as intervenções sejam feitas gradualmente, com sustentação científica dos riscos e formas de minimizar os impactos negativos.

Desse modo, cogita-se alargar o princípio da precaução, de forma que este possa ser trabalhado em prol das cidades, para seu desenvolvimento e crescimento, prevendo situações ou cogitando a possibilidade de situações que poderiam acarretar em danos ao meio ambiente (natural ou artificial), devendo negar seguimento aos empreendimentos antes de tomarem proporções de difícil reparação (PROVIN, 2019, p. 83). 
Consubstanciado neste princípio, o estudo de impacto ambiental (EIA), encontra respaldo constitucional no artigo $225, \S 1^{\circ}$, inciso IV, pois oferece às obras públicas e privadas capacidade para reconhecer e mitigar seus impactos negativos. Desse modo, percebe-se a influência de mais um instrumento à disposição dos entes municipais e da sociedade para que haja o controle preventivo das modificações do espaço urbano, privilegiando as funções da cidade.

Ambos, princípio da precaução e EIA, são recursos valiosos e necessários de fiscalização preventiva (RODRIGUES, 2018, p. 393) voltados ao Poder Público, à sociedade e aos órgãos de controle como ferramentas instrumentais do direito ao meio ambiente urbano salutar.

Igualmente pertencente à Política Nacional do Meio Ambiente, tem-se o Estudo de Impacto de Vizinhança (EIV) como instrumento avaliador de resultados que um empreendimento pode agregar a uma região. Ambos, EIA e EIV, subsidiam a proteção ambiental, por meio de pareceres técnicos (CAMPOS, 2019), preferencialmente multidisciplinares, dadas as constantes interações dos sistemas vivos.

A partir de um olhar mais detido na realidade do município, reitera-se a relevância de uma norma local profundamente vinculada aos planejamentos e interesses locais, como deve ser a instituição dos planos diretores.

\begin{abstract}
Além desses instrumentos tradicionais de precaução de danos, pode-se citar, no âmbito das cidades, o próprio plano diretor, que pela leitura do art. $182, \S 1^{\circ}$, da CRFB/88, é o "instrumento básico da política de desenvolvimento urbano" [...]. Logicamente, não se pode limitar a precaução municipal ao plano diretor, que requer um processo legislativo, mas toda e qualquer política urbana deve ser pautada pelo princípio da precaução, não de forma a evitar o desenvolvimento, mas de forma a prever a possibilidade de descoordenação do solo, ou ainda, quanto à falta de certeza da extensão do dano. Assim, a política urbana consegue cumprir com o objetivo constitucional de "ordenar o pleno desenvolvimento das funções sociais da cidade e garantir o bem-estar de seus habitantes, nos termos do artigo 182 da Carta Magna (PROVIN, 2019, p. 87).
\end{abstract}


O Plano Diretor Participativo do município de Fortaleza - CE, correspondente à Lei Complementar municipal 62 de 2009, ao inserir políticas públicas de mobilidade urbana e moradia em seu conteúdo, normatiza funções e, consequentemente, políticas públicas municipais sustentáveis.

O requisito de desenvolvimento sustentável se faz necessário e entrelaçado aos investimentos da política de desenvolvimento turístico, por exemplo, segundo o caput do artigo 52, com atendimento das dimensões social, econômica, cultural e ambiental dos programas e intervenções.

Estes instrumentos, utilizados para o controle das cidades pelas gestões municipais, encontram-se disponíveis há algum tempo. Contudo, como novidade colaboradora do papel fiscalizador, tem-se plataformas como a CITinova, desenvolvida pelo Ministério da Ciência, Tecnologia, Inovações e Comunicações (MCTIC), conjuntamente com outros autores, como o Programa das Nações Unidas para o Meio Ambiente (PNUMA).

A atribuição principal deste instrumento constitui-se no auxílio aos gestores públicos, notadamente os municipais, por meio de uma rede de apoio para planejamento urbano integrado. Significa dizer que as várias secretarias municipais comunicar-se-ão em prol de decisões mais unificadas, principalmente com o apoio tecnológico e aplicação de medidas sustentáveis (CGEE, 2020).

Neste momento, os olhares se voltam para a implementação de soluções tecnológicas e inovadoras que contribuam com a sustentabilidade das cidades, segundo o sítio oficial da CITinova. Um de seus projetos, o Programa Cidades Sustentáveis, visa ao apoio da municipalização dos Objetivos do Desenvolvimento Sustentável (MCTIC, GEF e PNUMA, 2018). Isso acontece pois atentam-se para 12 (doze) principais eixos os quais concretizam os Objetivos do Desenvolvimento Sustentável, contidos na Agenda 2030 da Organização das Nações Unidas.

Esses eixos foram estabelecidos a partir de indicadores que são instrumentos válidos para racionalizar políticas públicas e conferir-lhes 
sustentabilidade frente ao planejamento urbano local. A Administração Pública e os munícipes necessariamente farão uso desses indicadores para rever planos diretores e priorizar algumas obras em detrimento de outras (BURATTO, 2011), pois ferramenta dos sistemas de gestão ambientais.

\begin{abstract}
O uso de filtros ajuda a estabelecer o grau de significância, tais como: o aspecto ou o impacto ser objeto de legislação ambiental específica; ser uma preocupação manifestada pelos trabalhadores, vizinhos ou outras partes interessadas; ter saído do controle da organização no passado e causado acidentes; estar relacionado a um dos graves problemas globais, como a acumulação de gases do efeito estufa e a perda de biodiversidade. Os aspectos ou impactos ambientais que se enquadram em situações como essas são potencialmente significativos (BARBIERI, 2012, p. 166).
\end{abstract}

Neste mesmo sentido de organizar redes de informação e colaboração entre os entes públicos, o município de Fortaleza - CE, em abril de 2020, foi inserido no Mapa de Cidades Inteligentes da Organização para a Cooperação e Desenvolvimento Econômico (OCDE). As melhorias encontram-se amplamente ofertadas pela extensão do solo urbano e pertencem a diversos setores da vida no município, o que reforça a preocupação e o planejamento para o cumprimento das funções da cidade.

$\mathrm{O}$ estudo identifica mundialmente as cidades que investem em inovação, lidam com problemas urbanos e trabalham para melhorar a vida da população. $\mathrm{O}$ trabalho de identificação e compartilhamento é feito pela OCDE, que busca detectar os tipos de habilidades que as cidades estão trazendo para a prefeitura e como estão aplicando a inovação a uma ampla gama de áreas, desde melhoria do transporte público e a mobilidade. Na cidade, foram considerados serviços inteligentes utilizados diretamente pelo cidadão, como os estacionamentos em Zona Azul, aluguel de bicicletas, transporte público (bilhete eletrônico) e controle de trânsito, no quesito mobilidade urbana. $\mathrm{Na}$ área digital, os programas Fortaleza Digital e a plataforma Profuturo disponibilizam documentos e cursos EAD para a população. Já 
em saúde e educação, o agendamento de consultas e exames, a utilização de tablet e celular em aulas, matrículas online e acesso remoto a tarefas e conteúdos educacionais foram destacados. Por fim, o meio ambiente teve como destaque coleta de lixo, nível de ruído, nível dos rios, medidores inteligentes de energia e alertas da Defesa Civil (FORTALEZA, 2020).

A concepção de fiscalização não se encerra na direção do Poder Público para os administrados. Quanto a esta categoria de controle, também não se infere qualquer supremacia diante de um contexto já consolidado de necessária verificação das atividades públicas, em âmbitos interno e externo. Por esta razão, cumpre analisar o papel das Cortes de Contas no atendimento das funções da cidade pelas Administrações Públicas municipais.

\section{OS CONTROLES EXERCIDOS PELO TRIBUNAL DE CONTAS}

Em prol da harmonia do planejamento de políticas postas a serviço da população, cabe considerar de suma importância o controle, desta vez, sobre as atividades da Administração Pública municipal capaz de contribuir para a efetivação das funções da cidade.

Em conformidade com o artigo 75 da $\mathrm{CF} / 1988$ e anteriores, exerce-se o controle externo do ente municipal por meio da competência das Cortes de Contas dos Estados ou Municípios. A aprovação das contas, entre as atividades recorrentes nos tribunais, acompanha o progresso nos entendimentos dos operadores do Direito e ganha novos contornos de avaliação, não apenas no sentido da economicidade, como também de ações mais amplas de responsabilidade socioambiental.

Considerar o controle externo como mecanismo auxiliador do cumprimento das funções da cidade consiste em adequar um sistema previamente existente às demandas socioambientais e jurídicas do período, fator este que favorece a mudança de consciência e comportamento de 


\section{Entrole}

ambos os setores público e privado. As compras públicas servem como um bom medidor das prioridades e necessidades da população e das gestões públicas e aplicar conceitos que visem à sustentabilidade contribui para o alcance do direito ao ambiente equilibrado para as presentes e futuras gerações.

Coerente à esta visão sistêmica, e desta vez aprimorando o controle interno, tem-se a consolidação de programas de sustentabilidade implantadas nos tribunais, como o caso do Plano de Logística Sustentável do Tribunal de Contas do Estado do Ceará.

Dessa forma, elaborou-se o presente plano de logística sustentável do TCE/CE (PLS), que consiste em uma ferramenta de planejamento que permitirá estabelecer critérios de sustentabilidade e racionalização dos gastos institucionais e processos administrativos, resultante do esforço conjunto das unidades internas do TCE/CE, com o objetivo de construir um sistema de gestão pública cada vez mais sustentável e que exige mudanças culturais e de atitudes, consistindo o grande desafio em cruzar a linha do discurso à prática, concretizando-o em ações consistentes e efetivas (CEARÁ, 2019, p. 7).

Não apenas se realiza a fiscalização das gestões por critérios os quais visem à melhoria das condições de vida da sociedade, como também se exige que atuem de forma exemplar ao estipular metas sustentáveis cuja realização caiba ao próprio tribunal de contas.

Importa ressaltar que o planejamento sustentável ultrapassa as noções puramente socioambientais, visto que grandezas como o tempo podem ser incluídas como fatores sustentáveis. Exemplificando, significa estipular metas aos servidores humanamente possíveis de serem cumpridas ou mesmo o tempo de julgamento e dinâmica razoáveis aos processos administrativos, incluindo a possibilidade de atualização de sistemas físicos os quais não atendem a celeridade cabível no período atual.

Além disso, ultrapassa a aplicação em um órgão, ao estabelecer parâmetros de boas práticas públicas, possibilitando alianças em prol da má- 
xima efetividade da sustentabilidade dos municípios. Foi o ocorrido com a premiação do Selo TCE Ceará Sustentável à Assembleia Legislativa do Estado do Ceará, reconhecendo os benefícios oriundos da Agenda Ambiental na Administração Pública - A3P e que vai muito além da conscientização, a partir da efetiva implantação de sistemas de reaproveitamento de materiais e insumos, arborização do imóvel do órgão e destinação ecologicamente equilibrada dos resíduos.

O reforço de atuações de controle e incentivo via Administração Pública é certamente um dos meios mais efetivos de desenvolver as funções urbanísticas, enquanto definidoras dos novos parâmetros de moradia, trabalho, mobilidade e recreação nos centros urbanos.

Sendo assim, aponta-se a relevância de compreender o controle, nas suas formas externa e interna, como instrumentos colaboradores da aplicação das funções das cidades, podendo não ser considerados como controles com fins em si mesmos, mas consolidadores de direitos sociais relacionados às cidades.

Logo, defende-se que os controles exercidos pelas cortes de contas, munido de planos de sustentabilidade, são fortes instrumentos de verificação do cumprimento das funções da cidade pela Administração Pública Municipal.

\section{CONSIDERAÇÕES FINAIS}

A compreensão do espaço urbano sustentável perpassa necessariamente pelo atendimento das funções da cidade, quando executados melhoramentos urbanos ou políticas públicas, seja direta ou indiretamente. $\mathrm{E}$, para que o universo de serviços e intervenções que envolvem o habitar, o laborar, o circular e o recrear sejam replicados de maneiras sustentáveis, há a necessária existência de controles coerentes com as políticas planejadas. 
Em suma, não há como falar em resultados a longo prazo e de acordo com o ordenamento jurídico atual, olvidando-se uma fiscalização que se proponha a atentar para resultados para o futuro e, principalmente, a implementação de medidas de autocontrole sustentáveis.

Consideram-se os programas internos de boas práticas como um ponto de partida, o qual viabiliza ao órgão público muito mais que efetivar planejamentos sustentáveis com melhora prática dos índices, ser exemplo aos demais integrantes do setor público e ao setor privado. Percebe-se, portanto, a necessidade de olhares sistêmicos diante da aplicação de metas que visem o controle das atividades de modo a contribuir com ambientes saudáveis e facilitadores de direitos sociais como a moradia, o trabalho, a mobilidade urbana e o lazer.

A legislação vigente já requer um olhar voltado às demandas socioambientais, cabendo aos órgãos que compõem a Administração direcionar e endossar exemplos de medidas as quais fortaleçam o cumprimento das funções urbanísticas de maneira intergeracional.

No município de Fortaleza/CE, as intervenções urbanísticas encontram-se embasadas em programas de desenvolvimento sustentáveis os quais apresentam boas condições para o preenchimento das funções da cidade. A tendência, dadas as atuações das Administrações Públicas em geral, consiste em direcionar as novas estratégicas de gestão cada vez mais para o cumprimento de políticas públicas sustentáveis, integrando os diversos órgãos competentes e as funções dos espaços urbanos.

Logo, aplicar as funções da cidade como conceitos capazes de valorizar o ambiente urbano em prol da dignidade das pessoas que compõem esse sistema, juntamente com os órgãos e agentes públicos, constitui-se em pensar de maneira global, importando solucionar questões sem desatentar aos resultados porventura danosos e favorecendo a construção de espaços urbanos sustentáveis. 


\section{REFERÊNCIAS}

ARANHA FILHO, J. A. P. A competência do município em matéria ambiental e a sua responsabilidade na mitigação dos efeitos do aquecimento global. Revista de Direito Ambiental, São Paulo, v. 20, n. 84, p. 461-473, 2016.

ARENAS, N. S. Os desafios para a implementação das licitações sustentáveis na Administração Pública. Revista de Direito Ambiental, São Paulo, v. 21, n. 82, p. 121-136, 2016.

BARBIERE, J. C. Gestão ambiental e desenvolvimento sustentável: gestão ambiental empresarial. 3. ed. São Paulo: Saraiva, 2012.

BRASIL. Constituição da República Federativa do Brasil de 1988. Brasília, DF: Presidência da República, 1988. Disponível em: https:// bityli.com/VoGrV. Acesso em: 25 jan. 2020.

BRASIL. Lei $\mathrm{n}^{\circ}$ 8.666, de 21 de junho de 1993. Regulamenta o art. 37, inciso XXI, da Constituição Federal, institui normas para licitações e contratos da Administração Pública e dá outras providências. Diário Oficial da União, Brasília, DF, 22 jun. 1993. Disponível em: https://bityli.com/ aHj66. Acesso em: 27 abr. 2020.

BRASIL. Lei ${ }^{\circ} 12.349$, de 15 de dezembro de 2010. Altera as Leis nos 8.666, de 21 de junho de 1993, 8.958, de 20 de dezembro de 1994, e 10.973, de 2 de dezembro de 2004; e revoga o $\S 1^{\circ}$ do art. $2^{\circ}$ da Lei $n^{\circ}$ 11.273, de 6 de fevereiro de 2006. Diário Oficial da União, Brasília, DF, 16 dez. 2010. Disponível em: https://bityli.com/XyD5D. Acesso em: 27 abr. 2020. 
BRASIL. Tribunal de Contas da União. Acórdão no 1.752/2011-TCU-Plenário. Relator: Ministro André Luís de Carvalho. Brasília, DF: TCU, 2011.

BURATTO, A. L. Os Tribunais de Contas, o meio ambiente e o desenvolvimento sustentável: uma escuta à Administração Pública Municipal de Santa Catarina sobre o que é importante medir e monitorar. Revista Fórum de Direito Urbano e Ambiental, Belo Horizonte, v. 10, n. 56, p. 7-31, 2011.

CAMPOS, G. M. S. EIA a posteriori: a avaliação de impactos ambientais de empreendimentos consolidados. Revista de Direito Ambiental, São Paulo, v. 24, n. 95, p. 131-150, 2019.

CAVALCANTE, M. L. S. A. Administração Pública e Agenda Ambiental - A3P: considerações sobre a implementação nos órgãos públicos. Revista Controle, Fortaleza, v. 10, n. 1, p. 193-216. 2012.

CEARÁ. Plano de logística sustentável. TCE-CE: Fortaleza, 2020. Disponível em: https://Bityli.com/7oTFz. Acesso em: 30 jul. 2020.

CENTRO DE GESTÃO E ESTUDOS ESTRATÉGICOS. CITinova-MCTIC é destaque em Seminário Cidades Inteligentes e Sustentáveis. CGEE, Brasília, DF, 4 fev. 2020. Disponível em: https://bityli.com/ZYVQb. Acesso em: 5 maio 2020.

FARIAS, T. O exercício da competência administrativa ambiental pelos municípios. Revista Brasileira de Direito Municipal, Belo Horizonte, v. 18, n. 65, p. 119-124, 2017. 
FORTALEZA. Lei Complementar Municipal no 62, de 2 de fevereiro de 2009. Institui o Plano Diretor Participativo do Município de Fortaleza e dá outras providências. Diário Oficial do Município de Fortaleza, Fortaleza, 13 mar. 2009. Disponível em: https://bityli.com/Fbzny. Acesso em: 8 out. 2020 .

FORTALEZA. Fortaleza é inserida em mapa mundial de cidades inteligentes. Prefeitura de Fortaleza, Fortaleza, 9 abr. 2020. Disponível em: https://bityli.com/a5vRP. Acesso em: 5 maio 2020.

MINAS GERAIS. Tribunal de Justiça. Acórdão 1.0024.05.870488-3/0011 MG (1). Relator: Desembargador Maurício Barros. Belo Horizonte, 6 de março de 2007. Belo Horizonte: Tribunal de Justiça de Minas Gerais, 2007.

PROVIN, A. F. O princípio da precaução e as cidades. Revista de Direito Ambiental, São Paulo, v. 24, n. 94, p. 73-90, 2019.

RODRIGUES, J. S. Agenda ambiental na administração pública e licitações sustentáveis como instrumento de governança. Revista Controle, Fortaleza, v. 16, n. 2, p. 376-401, 2018.

SANTA CATARINA. Tribunal de Justiça. Agravo de instrumento: AI 14727 SC 1998/001472-7. Relator: Desembargador Anselmo Cerello. Florianópolis: Tribunal de Justiça, 1999.

SILVA, J. A. Curso de direito constitucional positivo. 34. ed. São Paulo: Malheiros, 2011.

SILVA, M. B. O.; KESSLER, M. S. A (in)eficácia das licitações públicas sustentáveis na administração pública Federal brasileira em face aos prin- 
cípios da isonomia e da economicidade. Revista de Direito Ambiental, São Paulo, v. 20, n. 84, p. 153-169, 2016.

ZAGO, M. A. S. O interesse local do município sob a égide da Constituição Federal de 1988: alguns apontamentos. Revista de Direito Administrativo Contemporâneo, São Paulo, v. 9, p. 177-202, 2014. 